\title{
Editorial
}

Lars Wågberg and Per Engstrand

\section{Change of Editor-in-Chief}

https://doi.org/10.1515/npprj-2018-0034

Professor Per Stenius has retired as Editor-in-Chief of Nordic Pulp \& Paper Research Journal (NPPRJ) from July 1st 2018. Per has been replaced by Professor Tom Lindström who is a well-known and highly respected researcher and professional in the research field of NPPRJ.

Professor Stenius who turned 80 in May this year claims that this is a reasonable reason for his retirement and who can oppose this claim. We can only thank Per for his dedication as Editor-in-Chief and for devoting so much time and concern for the benefit of the journal. With a never ending energy and professionalism Per has guided us through a new period of NPPRJ where the hunt for high impact factors has dramatically changed the reality of small but very important scientific journals such as NPPRJ. Per Stenius has also been instrumental in transferring the publication of NPPRJ to De Gruyter which has taken both time and endurance. Thank you for all this Per. We have all learned a lot from you and we will carry the tradition with NPPRJ forward and never give up the ambition to successively improve the quality as well impact factor and to show the importance of our journal in the changing landscape of the use of our forest asset in an efficient and ecofriendly way, in new and refined, bio-based products. Per Stenius will remain a member of our Editorial Board and International Scientific Advisory Board of NPPRJ which is excellent for the continuity of the journal.

At the same time we would also like to warmly welcome Professor Tom Lindström as Editor-in-Chief. We are convinced that Tom's solid scientific insight and impressive, global contact network will be a huge benefit for NPPRJ and we are looking forward to many years of excellent development of the journal together.

Lars Wågberg: On behalf of the Editorial Board and International Scientific Advisory Board of NPPRJ, KTH Royal Institute of Technology, Stockholm, Sweden, e-mail: wagberg@kth.se Per Engstrand: On behalf of the Editorial Board and International Scientific Advisory Board of NPPRJ, Mid Sweden University, Sundsvall, Sweden, e-mail: per.engstrand@miun.se 